\title{
Halofuginone inhibits phosphorylation of SMAD-2 reducing angiogenesis and leukemia burden in an acute promyelocytic leukemia mouse model
}

\author{
Patricia A. Assis ${ }^{1 \dagger}$, Lorena L. De Figueiredo-Pontes ${ }^{1 \dagger}$, Ana Silvia G. Lima', Vitor Leão ${ }^{1}$, Larissa A. Cândido ${ }^{1}$, \\ Carolina T. Pintão ${ }^{1}$, Aglair B. Garcia' ${ }^{1}$, Fabiano P. Saggioro², Rodrigo A Panepucci' ${ }^{1}$, Fernando Chahud ${ }^{2}$, \\ Arnon Nagler ${ }^{3}$, Roberto P. Falcão ${ }^{1}$ and Eduardo M. Rego ${ }^{1 *}$
}

\begin{abstract}
Background: Halofuginone (HF) is a low-molecular-weight alkaloid that has been demonstrated to interfere with Metalloproteinase-2 (MMP-2) and Tumor Growth Factor- $\beta$ (TGF- $\beta$ ) function and, to present antiangiogenic, antiproliferative and proapoptotic properties in several solid tumor models. Based on the fact that high levels of Vascular Endothelial Growth Factor (VEGF) and increased angiogenesis have been described in acute myeloid leukemia and associated with disease progression, we studied the in vivo effects of HF using an Acute Promyelocytic Leukemia (APL) mouse model.
\end{abstract}

Methods: NOD/SCID mice were transplanted with leukemic cells from hCG-PML/RARA transgenic mice (TM) and treated with HF $150 \mu \mathrm{g} / \mathrm{kg} /$ day for 21 days. The leukemic infiltration and the percentage of VEGF+ cells were evaluated by morphology and flow cytometry. The effect of HF on the gene expression of several pro- and antiangiogenic factors, phosphorylation of SMAD2 and VEGF secretion was assessed in vitro using NB4 and HUVEC cells.

Results: HF treatment resulted in hematological remission with decreased accumulation of immature cell and lower amounts of VEGF in BM of leukemic mice. In vitro, HF modulated gene expression of several pro- and antiangiogenic factors, reduced VEGF secretion and phosphorylation of SMAD2, blocking TGF- $\beta$-signaling.

Conclusion: Taken together, our results demonstrate that HF inhibits SMAD2 signaling and reduces leukemia growth and angiogenesis.

Keywords: Acute Promyelocytic Leukemia, Halofuginone, SMAD, TGF- $\beta$, VEGF, Angiogenesis

\section{Background}

Halofuginone (HF) is a low-molecular-weight quinazolinone alkaloid that has been demonstrated to present potent antitumor effects due antiproliferative $[1,2]$ and proapoptotic [3] properties. Treatment with HF impaired proliferation and induced apoptosis of several multiple myeloma cell lines and showed antitumor activity in a

\footnotetext{
* Correspondence: emrego@hcrp.fmrp.usp.br

${ }^{\dagger}$ Equal contributors

'Hematology and Oncology Divisions of the Department of Internal Medicine, Medical School of Ribeirão Preto, University of São Paulo, Ribeirão Preto, SP 14049900, Brazil

Full list of author information is available at the end of the article
}

myeloma xenograft mouse model [3]. In addition, HF antiangiogenic properties also have been shown to contribute to control of tumor growth [4-6]. In a rat brain tumor model, HF treatment markedly reduced vascularization and vessel maturation resulting in reduced tumor burden and metastasis [6].

Angiogenesis is one of the most important mechanisms of tumor progression $[7,8]$ and has been associated to development of hematological malignancies [9]. Several studies have reported an increase in bone marrow (BM) microvessel density (MVD) and high VEGF (Vascular Endothelial Growth Factor) expression in multiple myeloma [10], nonHodgkin lymphoma [11], and acute leukemias [12, 13]. 
Particularly, in acute myeloid leukemia (AML), high levels of VEGF and increased MVD were found in leukemic BM biopsies [12] and correlated with lower rates of complete remission and lower overall survival [14]. In a study analyzing 12 BM biopsies from patients with acute promyelocytic leukemia (APL), Kini et al. [15] detected increased MVD associated with high VEGF expression. After standard treatment with ATRA (all-trans retinoic acid), VEGF levels and BM MVD were normalized. Another clinical study with 17 new cases of APL associated the efficacy of the arsenic trioxide treatment with its antiangiogenic effect, demonstrated by the reduced MVD in the BM and increased survival [16].

Despite the fact that all-trans retinoic acid (ATRA) is largely applied for the treatment of APL, the use of ATRA alone does not achieve long-term remission $[17,18]$. Thus, associations of ATRA with chemotherapy or arsenic trioxide have been more successful in improve long-term survival [19]. However, these treatment regiments have limited application for elderly patients or those with serious heart conditions [20]. In addition, the therapy with arsenic trioxide is not available in several developing countries [21] and the $10-20 \%$ of patients treated with ATRA-chemotherapy or ATRA-arsenic trioxide association will relapse [22, 23]. Therefore, the development of new strategies for APL therapeutics is necessary and angiogenesis is a potential target to achieve a better outcome.

The exact mechanism by which HF impairs angiogenesis has not yet been fully characterized. Elkin et al. [24] reported that HF treatment led to the reduction in metalloproteinase-2 (MMP-2) expression and inhibition of bladder carcinoma metastasis in an animal model. However, HF effects may not be specific to malignant tissues, since the implant of silicone coated with HF resulted in reduced expression of MMP-2, bFGF and TGF- $\beta$ in normal muscle [25]. In APL the TGF- $\beta$ pathway is deregulated by the cytoplasmic PML isoform (cPML) [26] and we have demonstrated that HF inhibited cell proliferation and induced apoptosis in the APL cell line NB4 through modulation of TGF- $\beta$-target genes, such as c-Myc and p21 [1]. In addition, it is noteworthy to point out that the promoter region of the VEGF gene contains DNA-binding sequences for hypoxia-inducible factor 1 alpha (HIF-1 $\alpha)$ and for the TGF- $\beta$-signaling mediators SMADs $[27,28]$. Thus, activation of TGF- $\beta$ pathway may be associated with increased VEGF expression and angiogenesis in acute leukemias. Here we analyzed the in vivo antileukemic effect of HF and its association with the modulation of proangiogenic and antiangiogenic factors using APL as a bone fide example of acute leukemia with increased angiogenesis.

\section{Methods}

Halofuginone

Halofuginone (HF-dl-trans-7-bromo-6-chloro-3-(3-(3-hydroxy-piperidyl)acetonyl)-(3H)-quinazolinone hydrobromide) was solubilized in lactic acid priors to dilute into phosphate buffer solution. In vitro $\mathrm{ED}_{50}$ was previous determined [1] in vivo doses were delineated based on previous reports of the use of this drug in solid tumors and fibrosis models [29-32].

\section{Mice and leukemia transplant model}

BM angiogenesis was first analyzed in leukemic hCGPML/RARA transgenic mice (TM). Notably, in this transgenic model, a lethal form of leukemia that closely resembles human APL occurs after a long pre-leukemic phase (12-15 months) and affects only $10-15 \%$ of the TM [33]. To analyze in vivo effects of HF we developed an APL transplanted model. Thus, NOD/SCID mice aged 10 to 12 weeks were irradiated with 250 cGy and 24 hours later, $2 \times 10^{6}$ viable cells from leukemic hCGPML/RARA transgenic mice (TM) were intravenously injected. Twenty-four hours after transplantation, NOD/ SCID mice were then submitted to daily treatment with $150 \mu \mathrm{g} / \mathrm{kg} /$ day $\mathrm{HF}(n=5)$ or vehicle only $(0.9 \%$ $\mathrm{NaCl} ; n=5)$ as an intraperitoneal injection for 21 consecutive days. Previous experiments were performed to confirm leukemic infiltration in transplanted animals and to test the efficacy and toxicity of HF. All animal experiments using mice were conducted according to national guidelines for the care and use of laboratory animals (Brazilian College of Animal Experimentation) and were approved by the institutional Animal Experimentation Ethics Committee (protocol number 062/2008).

\section{Cell culture}

NB4 cells, a permanent cell line harboring PML-RAR $\alpha \mathrm{t}$ (15;17), characterizing an APL cell line [34], was used for in vitro assays. Briefly, cells were cultured in RPMI 1640 with $10 \%$ fetal calf serum (FCS, Gibco, BRL, UK). Human Umbilical Vein Endothelial Cells (HUVEC) were maintained in EBM medium supplemented with $20 \%$ FCS [35]. All cells were maintained at $37{ }^{\circ} \mathrm{C}$ under $5 \%$ $\mathrm{CO}_{2}$.

\section{Quantification of VEGF, angiogenin, and TGF- $\beta$}

NB4 cells were treated with HF for 72 hours at doses ranging from 25 to $100 \mathrm{ng} / \mathrm{mL}$. VEGF, angiogenin and TGF- $\beta$ concentrations in supernatants were determinate by CBA (Cytometric Bead Array, BD Biosciences, San Jose, CA, USA) and/or ELISA (BD Biosciences, San Jose, CA, USA), following manufacturer's recommendations.

\section{Phospho-SMAD2 (P-SMAD2) identification}

The phosphorylation of SMAD2 was assessed in total protein extracts obtained from NB4 cells treated with 50, 100, and $200 \mathrm{ng} / \mathrm{mL}$ doses of HF for 6,12 , and 24 hours. We used the PathScan ${ }^{\circ}$ Phospho-Smad2 (Ser465/ 467) Sandwich ELISA Kit (Cell Signaling, Danvers, MA, 
USA) that provides the P-SMAD2 level as a direct absorbance reason. To assess the phosphorylated protein, TGF- $\beta 1$ cytokine (Sigma-Aldrich, St. Louis, MO, USA) was added to the culture $(1 \mathrm{ng} / \mathrm{mL})$ one hour before the ending of HF treatment.

\section{Real time PCR and PCR array}

mRNA expression was assessed by real time PCR. Briefly, total RNA was isolated using Trizol reagent (Invitrogen, Carlsbad, CA, USA) and was reverse transcribed using the cDNA High Capacity Archive kit (Applied Biosystems, Foster City, CA, USA). cDNA samples were used to quantify gene expression using specific primers and probes TaqMan ${ }^{\circ}$ (Applied Biosystems, Foster City, CA, USA). Gapdh was included as endogenous internal control. PCR array was performed using the angiogenesis RT2 Profiler $^{\text {Tm }}$ PCR Arrays kit (SA Biosciences, Frederick, MD, USA), in which each cDNA sample was processed in a 96-well plate containing 84 angiogenesis-related genes and B2M, HPRT1, RPL13A, $A C T B$, and GAPDH were included as endogenous internal controls in all plates. mRNA expression of nontreated cells or non-leukemic mice are expressed as Fold Change $=1$. Amplification was performed in plate duplicates in a 7500 Real-Time PCR System (Applied Biosystems, Foster City, CA, USA).

\section{Immunohistochemistry staining for VEGF in bone marrow sections}

Vertebra samples were collected from mice, fixed and serial $5-\mu \mathrm{m}$ sections were prepared in paraffin. Immunohistochemistry was performed with primary anti-VEGF antibodies (Santa Cruz Biotechnology, Santa Cruz, CA, USA) and anti- $\alpha$-actin (for TM mice) and anti-CD34 (for transplante mice) (Becton Dickinson, San Jose, CA, USA) at 1:500, 1:800 and 1:50, respectively. Peroxidase activity was revealed by $3,3^{\prime}$-diaminobenzidine as chromogen. Alpha-actin and CD34 expression was used for assessing microvessel density (MVD), quantified as the number of microvessels $/ \mathrm{mm}^{2}$ after analyzing three high-power fields $(400 \times)$.

\section{Analysis of the hematological responses to $\mathrm{HF}$ in vivo}

At day 21 mice were sacrificed after being subjected to a cardiac puncture to obtain peripheral blood [36] samples. Age-matched NOD/SCID healthy animals were used as controls (WT; $n=3$ ). Automated counts for white blood cells (WBC) were performed using a T-890 Coulter cell counter (Coulter Corporation, Hialeah, FL, USA), and differential counts were obtained from Leishman-Wright-Giemsa-stained smears. For morphological analysis, 100 cells of PB were counted, and then myeloid cells were classified as immature, intermediate, or mature, according to the Bethesda criteria [37]. Bone marrow (BM) cells were obtained by flushing of the bone cavities and the cells were used for cytospin slide preparation and staining with Leishman-Wright-Giemsa. Imprint slides of the spleen were also performed to quantify the hematological response to HF.

\section{Immnunophenotyping of bone marrow cells}

BM cells were characterized by immnunophenotyping using the following combinations of mAbs: CD117-PE/ CD16/32-FITC/CD45-Per-CP; CD11b-PE/Gr-1-FITC/ $\mathrm{CD} 45-\mathrm{PerCP}$. Fluorochrome-conjugated isotypic antibodies were used as negative controls. All antibodies were purchased from BD Biosciences Pharmingen (San Diego, CA, USA). A minimum of 10,000 events/tube were acquired with a FACScalibur flow cytometer. Viable CD45-positive cells were gated and the percentage of each cell subset was determined using the CellQuest software (Becton Dickinson).

\section{ChIP assay}

NB4 cells were stimulated with Halofuginone (200 ng/ $\mathrm{mL})$, TGF- $\beta$ ( $50 \mathrm{ng} / \mathrm{ml})$ or Halofuginone $(200 \mathrm{ng} / \mathrm{mL})+$ TGF- $\beta$ (50ng/mL), for 6 hours and the chormatin immunoprecipitation was performed with Magna ChIP ${ }^{\text {mix }} \mathrm{G}$ (Millipore, Billerica, MA, USA) according to the instructions of manufacturer. Briefely, the crosslink was made with $1 \%$ formaldehyde followed by addition of $125 \mathrm{mM}$ glicine to quench unreacted formaldehyde. Samples were then resuspended in cell lysis buffer containing Proteases Inhibitors before addition of Nuclear Lysis Buffer. The final lysates were sonicated to shear the genomic DNA into around 200-1000pb fragments. ChIP assay was performed on the supernatants by addition of $5 \mu \mathrm{g}$ of each antibody: Anti-P-Smad2 (phospho S467 - ab192191); Anti-Smad2 + Smad3 (ab63672); Anti-HIF-1 $\alpha$ (ab2185) and IgG rabbit polyclonal (ab27478). Primers for Vegf promoter region were custom designed (Additional file 1: Table S1). Graphics show Fold enrichment over IgG antibodie control for each sample and primer. Primers were purchased from Sigma- Aldrich (St. Louis, MO, USA).

\section{Statistical analysis}

All experiments were evaluated by analysis of the variance (ANOVA) between groups followed by the Bonferroni's correction post-test or Mann-Whitney unpaired t-test. In all comparisons, a significance level of $P<0.05$ was considered to be significant. Statistical analyses were performed using SPSS 13.0 software.

\section{Results}

Angiogenesis is aberrantly increased in the APL transgenic mouse model

Based on the demonstration of high levels of VEGF in BM biopsies from APL patients [15], we first investigated 
VEGF expression in an APL transgenic mouse (TM) model expressing the PML/RAR $\alpha$ fusion gene under the control of human cathepsin gene promoter (hCG) [33, 38]. Fig. 1a and b show the immunohistochemistry analysis of VEGF expression in leukemic and control BM TM samples. There was a striking increase in the number VEGF positive cells in leukemic BM and, by correlating with $H \& E$ staining (not shown), it was possible to identify that most VEGF positive cells were leukemic blasts. In addition, the number of microvessels $/ \mathrm{mm}^{2}$ in $\mathrm{BM}$ sections of leukemic TM was higher than that of controls (mean of $65.2 \pm 38.44$ vs. $18.25 \pm 7.66$ microvessels $/ \mathrm{mm}^{2}$, respectively). These results demonstrate that the PML-RAR $\alpha$ TM model reproduces the increased MVD and VEGF reported in human APL.

\section{Halofuginone modulates expression of genes associated with angiogenesis}

Jordan and Zeplin, showed that HF significantly reduces the gene expression of pro-angiogenic factors in physiologic conditions in muscle cells [25]. In order to evaluate the effect of HF in leukemic cells, we treated the APL cell line NB4 and performed a screening of gene expression using the PCR array method analyzing 84 predefined genes involved in angiogenesis (Additional file 2: Table S2). Among the 40 genes whose expression was modulated by incubation with $\mathrm{HF}$ at the dose of $50 \mathrm{ng} / \mathrm{ml}$ for 6 hours, 16 encoded for growth factors and receptors, 6 for cytokines, 5 for proteases inhibitors and matrix proteins, 4 for adhesion molecules and 3 for transcription factors. As highlighted in Fig. 2a and b the expression of most proangiogenic factors was decreased and the antiangiogenic factors TIMP2 and CXCL10 was increased at all HF concentrations. The largest differences were noted for HIF- $1 \alpha$ (mean of $0.48 \pm 0.33$ fold change), HGF (0.12 \pm 0.056 ), angiopoetin-1 (ANGPT-1: $0.38 \pm 0.19$ ), angiopoetin-2 (ANGPT-2: $0.57 \pm 0.16)$, TIMP2 $(2.1 \pm 0.74$ ) and CXCL10 (16.5 \pm 5.4$)$. HF dose dependent effect was detected for VEGFA, TIMP2 and CXCL10.
We next evaluate if the HF effects over gene expression would extend to endothelial cells. Interestingly, HUVEC cells treated with the aforementioned HF concentrations, showed increased VEGF gene expression $(9.3 \pm 3.34$; at $100 \mathrm{ng} / \mathrm{mL})$ and protein secretion (Fig. 3a and $3 b)$. Moreover, ANGPT-1, HIF-1 $\alpha$, HGF, TIMP2 and CXCL10 did not show significant change in gene expression while ANGPT-2 showed increased expression (3.5 \pm 1.02; at $200 \mathrm{ng} / \mathrm{mL}$ ).

\section{Halofuginone inhibits pro-angiogenic mediators in the APL cell line NB4}

Previously, we have demonstrated that HF at concentrations higher than $75 \mathrm{ng} / \mathrm{ml}$ induced TGF- $\beta$ and TGF $\beta-\mathrm{R} 2$ protein expression in NB4 cells [1]. TGF- $\beta$-cell responses are coordinated through SMADs phosphorylation, which translocate to nucleus and work as transcription factors [39]. Thus, we further analyzed the phosphorylation of SMAD2 in NB4 cells. HF treatment for 6 and 24 hours impaired phosphorylation of SMAD2 (Fig. 4a), which was a dose- and time-dependent effect that lasted at least for 24 hours. Based on the fact that the promoter region of the VEGF gene contains DNA-binding sequences for SMADs [27, 28] and the previous report that the NB4 cells secretes high levels of VEGF [15], we evaluated the effect of HF treatment in NB4 VEGF production. Quantification of cell-culture supernatants of NB4 cells treated with HF for 72 hours showed that VEGF levels were strongly reduced using HF concentration of $200 \mathrm{ng} / \mathrm{mL}$. (Fig. 4b). In order to verify if SMAD2 has a role as transcription factor for VEGF expression in NB4 cells, we performed a ChIP assay using antibodies for the phosphorylated form of SMAD2 (P-SMAD2) and for the heterodimer SMAD2/3. Analysis of approximately 3,700 pb neighboring the transcription start site (TSS) of VEGF gene showed that, NB4 stimulation with TGF- $\beta$ increases P-SMAD2 binding in several sites upstream and downstream VEGF. HF treatment prior TGF- $\beta$ stimulation enhanced P-SMAD2 (Fig. 4c). On the other hand,
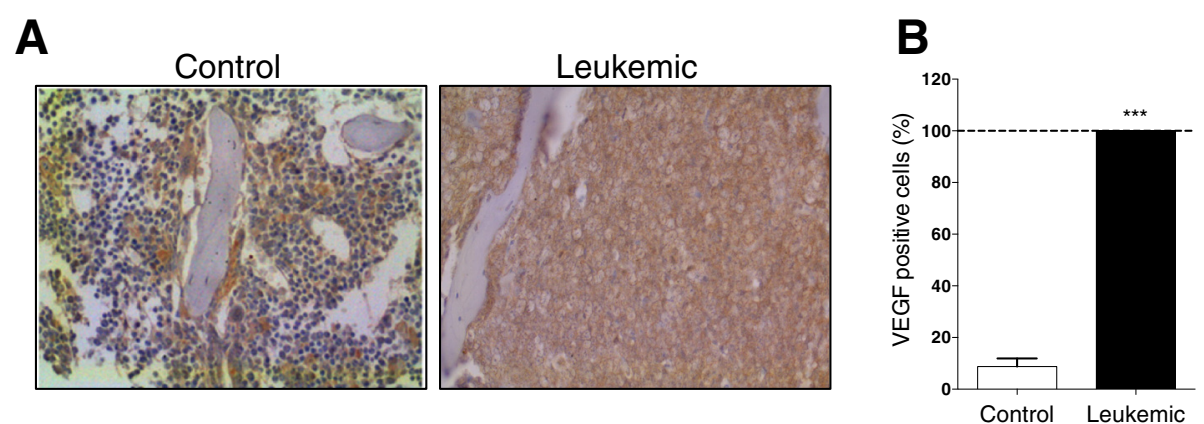

Fig. 1 Expression of the pro-angiogenic mediator VEGF is increased in APL transgenic mouse model. a Bone marrow (BM) samples of non-leukemic control hCG-PML-RARa transgenic mice (TM) and hCG-PML-RARa transgenic mice at leukemia diagnosis. b Percentage of VEGF positive cells detected by VEGF-staining by immunohistochemistry and analysis of three microscopic fields (400x) (in brown). ${ }^{* *} \mathrm{P}<0.0001$ (t-test) 
A

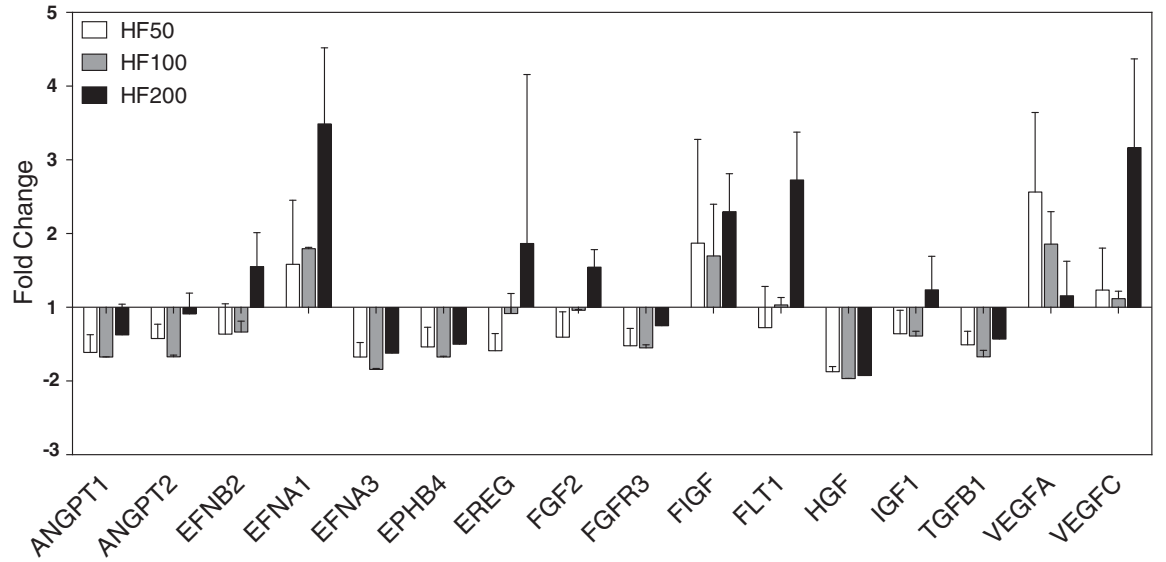

B

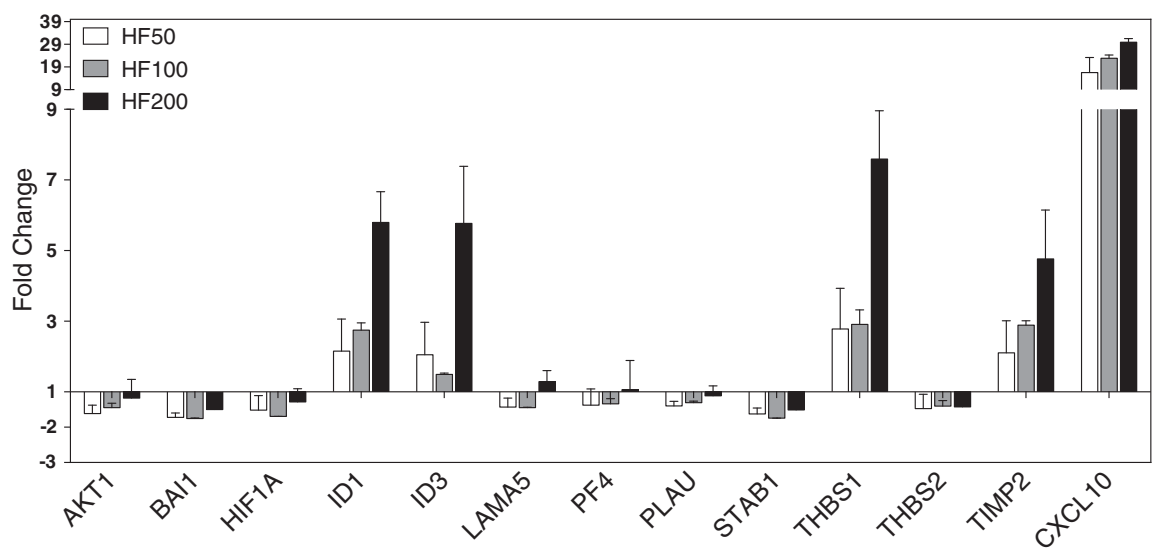

Fig. 2 Gene expression of angiogenic factors is down-modulated by halofuginone. a, b NB4 cells were treated with 50 , 100 or 200 ng/mL of HF for 6 hours and mRNA expression of angiogenesis determinants was assessed by PCR array. Graphic shows genes with greater differential expression compared to nontreated cells (Fold change $=1$ ). Data are representative of two independent experiments (error bars, s.e.m.)

ChIP assay using anti-SMAD2/3 did not showed binding of unphosphorylated SMADs upon stimulation with TGF- $\beta$, however the previous treatment with HF showed increase increase in two sites $(2,500$ and 3,600 upstream TSS) (Fig. 4d). Similarly, HIF-1 $\alpha$ binding was not induced only by TGF- $\beta$ stimulation, and was enhanced with $\mathrm{HF}$ treatment (Additional file 3: Figure S1A). Anti-RNA Polimerase II was used as a control of the ChIP assay (Additional file 3: Figure S1B), and showed increased binding in all the sites analyzed upon TGF- $\beta$ stimulation with or without HF treatment.

\section{Halofuginone displays an anti-leukemic effect in the in vivo model of APL}

To investigate whether the anti-angiogenic properties of HF resulted in anti-leukemic effects in APL, we used a transplant model of PML-RAR $\alpha$ leukemic cells in NOD/ SCID mice. All recipients developed extensive BM and spleen infiltration, leukocytosis and succumbed of the disease within 30-40 days [1]. This strategy was necessary due to the long latency and low penetrance of the transgenic model, which require the observation of a large cohort of TM. Therefore, recipient mice were treated with HF i.p. for 21 days starting on Day 2 post transplant and at the end of treatment mice were sacrificied. Treatment with HF significantly reduced white blood cell (WBC) counts in leukemic mice (Fig. 5a). [33]. Morphological analysis of Leishman-Wright-Giemsa-stained slides of BM and spleen imprints confirmed the infiltration of immature cells in leukemic animals and showed a significant reduction of this cell pattern in the HF-treated mice (Fig. 5b). The immunophenotypic analysis of BM showed that HF-treated mice had a higher percentage of more differentiated $\mathrm{CD} 11 \mathrm{~b}^{+} / \mathrm{Gr}-1^{+}$myeloid cells and lower of $\mathrm{CD} 117^{+} \mathrm{CD} 16 / 32^{+}$(previously defined as murine leukemic cells [40]) compared to leukemic non-treated mice (Fig. 5c, 


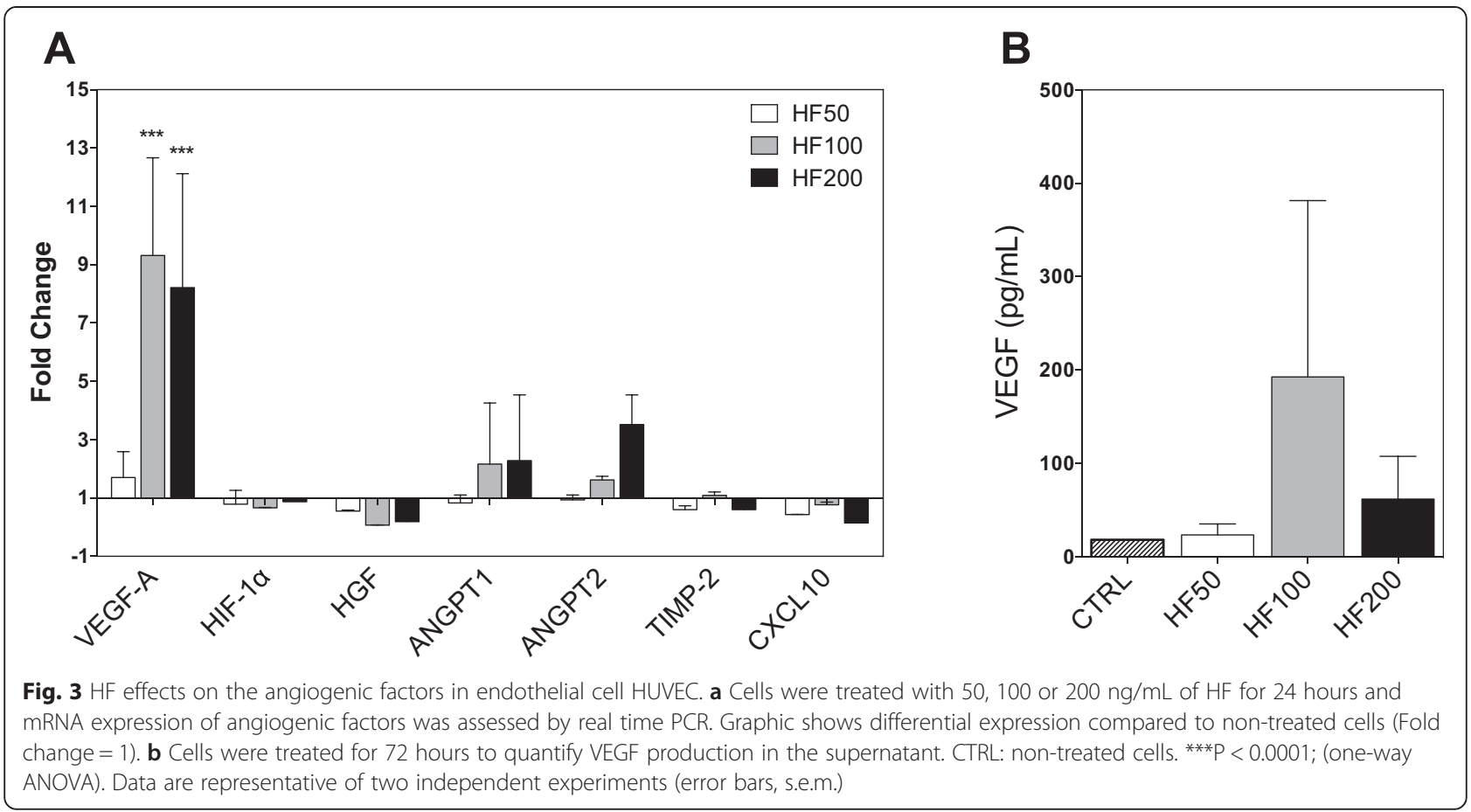

$\mathrm{d}$ and e). Finally, in addition to the anti-proliferative action, the reduction of leukemia burden observed with $\mathrm{HF}$ treatment correlated with antiangiogenic effects. Quantitative and qualitative expression of VEGF by immunohistochemistry showed a reduced number of $\mathrm{VEGF}^{+}$cells and lower VEGF expression in BM sections from HFtreated mice than in non-treated control (Fig. 6a). Likewise, in our findings with the leukemic PML-RAR $\alpha$ TM, most of the VEGF positive cells corresponded to immature cells (Fig. 6b). Nevertheless, the reduction of the MVD in HF-treated mice did not reach statistical significance $\left(158 \pm 32.5\right.$ vs. $118 \pm 35$ microvessels $/ \mathrm{mm}^{2}$ in controls $(n=5)$ and treated leukemic mice $(n=5)$, respectively). In the other hand, PCR analysis of BM samples also showed reduction in VEGF, HIF- $1 \alpha$ and ANGPT-2 gene expression in HF-treated mice (Fig. 6c), whereas ANGPT-1, HGF, TIMP2 and CXCL10 had no change in leukemic mice (data not shown).

\section{Discussion}

Here we report that HF reduced tumor burden in an APL mouse model as showed by the cytomorphological and immunophenotyping analysis of the BM after 21 days of treatment. This is the first study to show that leukemic hCG-PML/RARA TM had increased VEGF expression in $\mathrm{BM}$, reinforcing that VEGF may be a mediator supporting leukemogenesis [41]. Using a transplant model of PML-RAR $\alpha$ leukemic cells, the treatment with $\mathrm{HF}$ reduced the number of $\mathrm{VEGF}^{+}$cells and VEGF gene expression in BM of leukemic mice.
However, HF treatment did not result in a significant reduction of MVD. This may be a consequence of the transplant model used, which led to a massive infiltration of the BM with a shorter survival compared to solid tumor models. In this regard it is worthy pointing out that in the study by Elkin et al. the animals with bladder cancer were treated with oral HF for 26 and 29 weeks [42].

In addition, the treatment of the endothelial cell HUVEC with HF did not change the gene expression of ANGPT-1, HIF-1 $\alpha$, TIMP2 and CXCL10, whereas increased VEGF gene expression and protein secretion. These data suggests that HF effects may present variation according to the cell type, which is in accord with the previous demonstrated increase in VEGF production by fibrotic liver cells from rats treated with HF [43]. Furthermore, it is well established that tumor cells-derived VEGF stimulates endothelial cells to produce VEGF [44]. Considering that the basal production of VEGF showed by NB4 cells is over 100-fold higher, the induction of VEGF by HF treatment in endothelial cells may not have impact in the angiogenesis process.

In non-APL AML Schuch et al. [45] demonstrated that VEGF administration resulted in enhanced tumor growth and vascularization whereas treatment with a VEGF antagonist soluble NRP-1 inhibited tumor angiogenesis and growth in a chloroma mouse model. Moreover, these authors showed that the injection of adenovirus encoding NRP-1 reduced the leukemic burden and prolonged the survival of leukemic mice. 

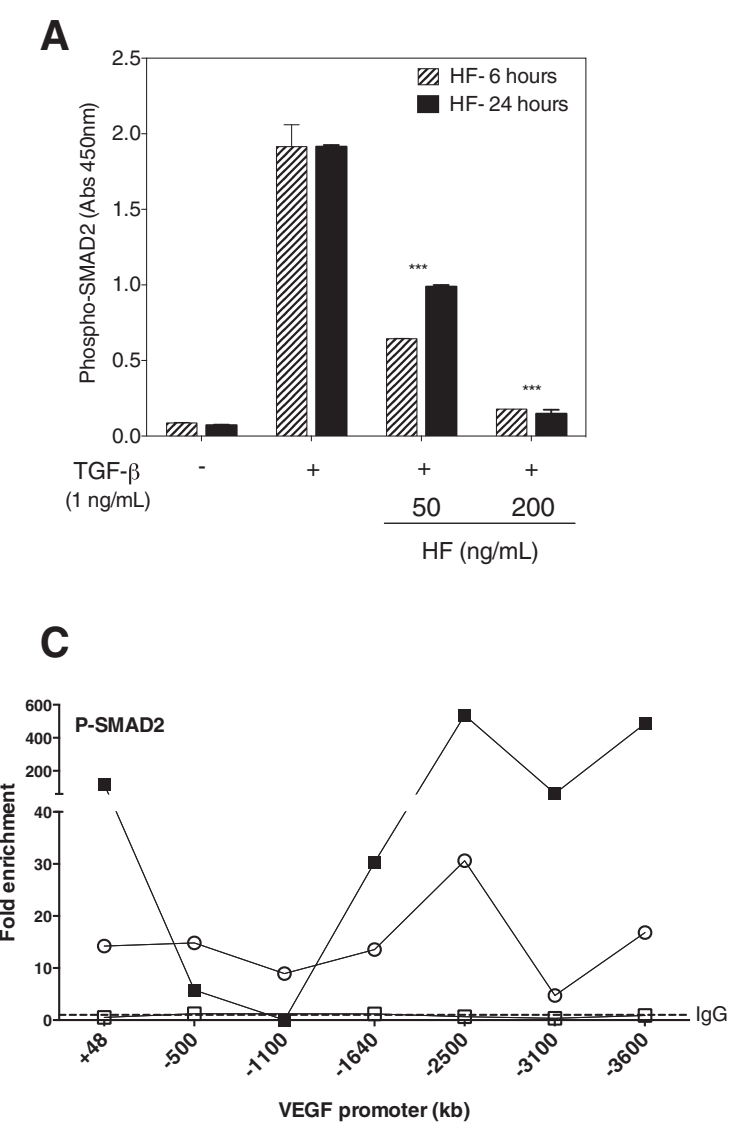

B
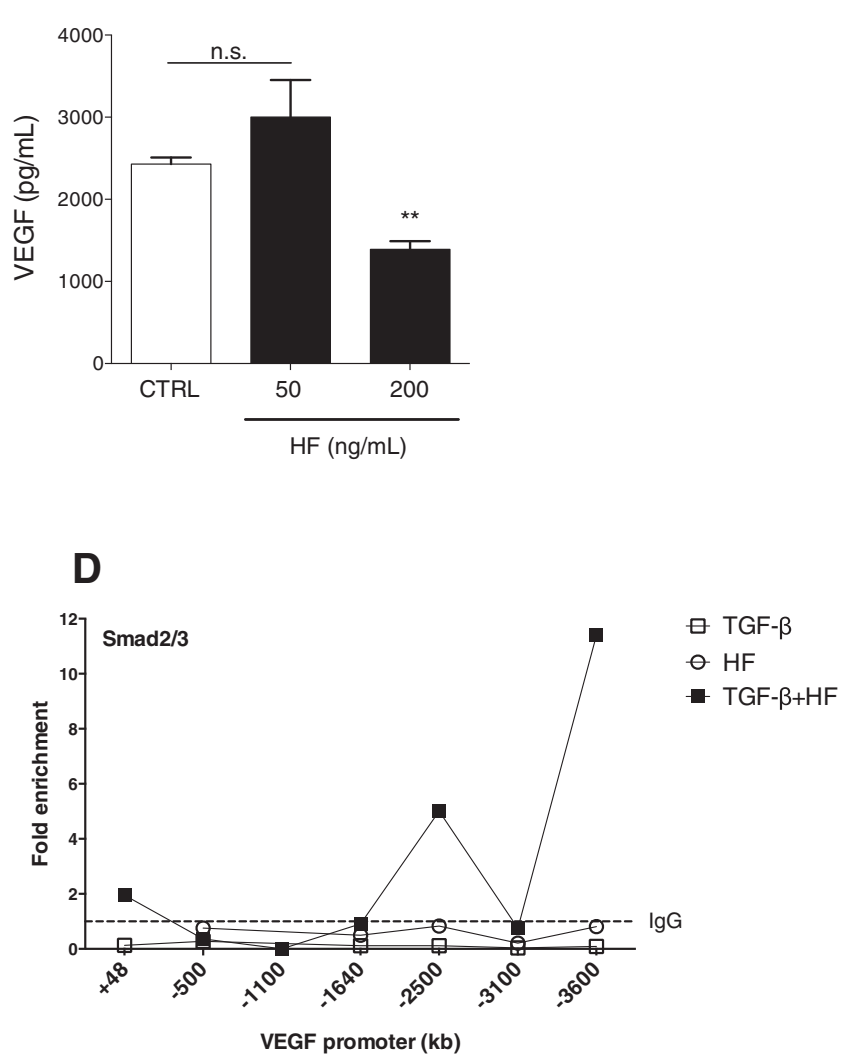

Fig. 4 Halofuginone inhibits pro-angiogenic mediators in NB4 cells. a Phospho-SMAD2 identification assessed by ELISA in NB4 cells treated with 50 and $200 \mathrm{ng} / \mathrm{mL}$ of HF for 6 and 24 hours hours and TGF- $\beta(1 \mathrm{ng} / \mathrm{mL})$ was added to the cultures 1 hour before. $\mathbf{b}$ Concentration of VEGF determined by CBA in the supernatant of NB4 cells treated with 50 and $200 \mathrm{ng} / \mathrm{mL}$ doses of HF during 72 hours. CTRL: non-treated cells. C, d ChIP assay using antibodies to P-Smad2 and Smad2/3. NB4 cells were treated with $200 \mathrm{ng} / \mathrm{mL}$ of HF for 6 hours, or treated with $200 \mathrm{ng} / \mathrm{mL}$ of HF for 6 hours and stimulated with TGF- $\beta(1 \mathrm{ng} / \mathrm{mL})$ in the last hour, or only stimulated with TGF- $\beta$. Graphics showing a PCR amplification of ChIP products using a series of primer pairs covering the upstream and downstream the transcription start site (TSS) of Vegf. Data is represented as fold enrichment to IgG control antibody. ${ }^{* *} P<0.001,{ }^{* *} \mathrm{P}<0.0001$; (one-way ANOVA). Data are representative of two $\mathbf{a}$ and three $\left.\mathbf{b}\right)$ independent experiments (error bars, s.e.m.)

Recently, Oka et al. described a high level of VEGF-A in the serum of an APL patient at diagnosis and the ex-vivo treatment with an anti-VEGF-A reduced leukemic cell proliferation [46]. Unfortunately, in the phase II HOVON/ SAKK AML study, the administration of the anti-VEGF agent bevacizumab along with standard chemotherapy did not result in better outcome in older patients [47]. Thus, despite experimental results indicating that VEGF have a potential therapeutic benefit, the HOVON/SAKK study suggests that inhibition of VEGF may not be sufficient to control angiogenesis or tumor growth.

Considering HF antiangiogenic properties, we used a PCR array to screening angiogenic mediators in the APL cell line NB4. Our data showed a down-regulation mediated by $\mathrm{HF}$ in several pro-angiogenic factors, including HFG, HIF-1 $\alpha$, ANGPT-1 and -2 , whereas the anti-angiogenic factors TIMP2 and CXCL10 were over expressed. Indeed, HGF is a well-recognized proangiogenic mediator which inhibition reduces tumor growth and metastasis [48], as well HIF-1 $\alpha$, which is associated with poor prognosis in cancer due stimulation of $\mathrm{VEGFR}^{+}$ cells migration to the tumor [49]. Contrary, CXCL10 and TIMP2 had they antiangiogenic potential demonstrated. Mice with fibrosarcoma treated with CXCL10 combined with hypothermia presented reduced tumor burden and MVD [50], whereas the MMP2-inhibitor TIMP2, have been recently described as important prognostic factors in acute lymphoblastic leukemia [51]. In the leukemia mouse model, we did observe increased gene expression of VEGF, HIF- $1 \alpha$ and ANGPT-2, which were significantly reduced after HF treatment. These PCR data support that HF antiangiogenic effect implicates multiple targets, as demonstrated by Jordan ans Zeplin [25], MMP-2, bFGF and TGF$\beta$ were down-modulated by HF in physiologic conditions.

On the other hand, addition of HF to NB4 cells cultures did not result in morphological differentiation [1] 


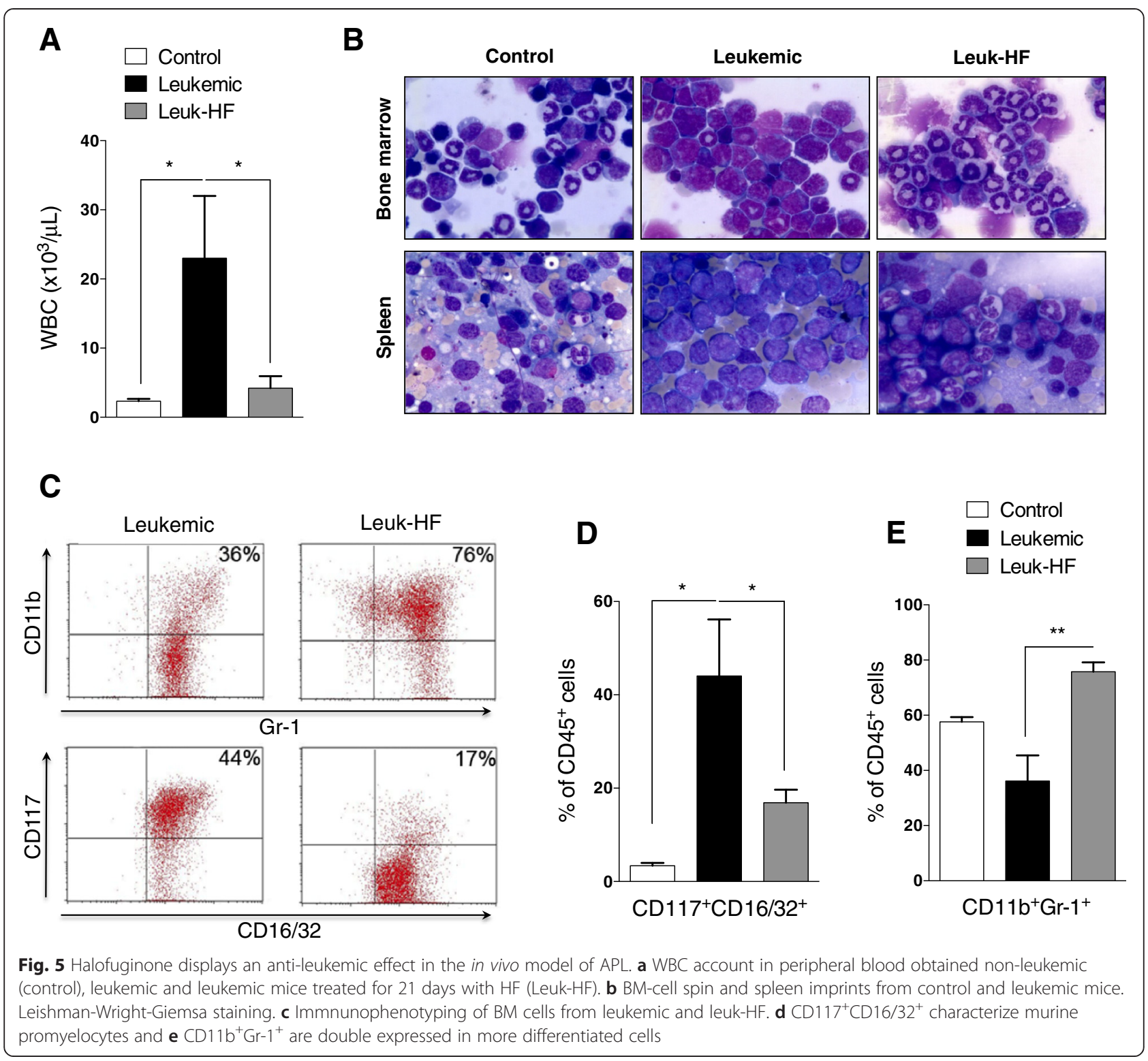

likewise, no differentiation was observed in BM and blood smears of recipient mice at seven and 14 days of HF treatment (data not shown). Therefore, we believe that increase in differentiated cells in BM of HF treated mice reflects the restoration of normal hematopoiesis secondary to the significant reduction of the leukemic infiltration. Together, our results corroborate with previous studies reporting the anti-proliferative and proapoptotic actions of HF in solid tumors [32, 52] and in leiomyoma cell line [53] and with recent observations from our group demonstrating that HF induced the blockade of cell cycle progression at G1/S transition and apoptosis in NB4 cells [1]. Here we showed that NB4 cells treated with HF had SMAD2 phosphorylation abrogated indicating that the TGF- $\beta$-signaling was inhibited, which is in agreement with previous studies [54-56]. It is proposed that VEGF gene expression is targeted by TGF- $\beta$ - signaling [57-59] and that low concentration of TGF- $\beta$ cooperate with VEGF to stimulate epithelial cell proliferation and migration [60]. Thus, one possible explanation for the VEGF reduction induced by HF is the inhibition of the TGF- $\beta$ signaling. One result suggest that HF acts by decreasing SMAD-2 phosphorylation triggered by TGF- $\beta$. However, ChIP analysis showed that, despite reduction of SMAD phosphorylation, HF treatment increases P-SMAD2 binding to VEGF promoter region. Importantly, it has been demonstrated that SMAD2 is not required for VEGF gene expression, and that SMAD3 is the potential transcription factor linking TGF- $\beta$-signaling and VEGF [57].

It has been proposed that the PML-RAR $\alpha$ fusion protein, similarly to cPML interacts and co-localizes with SMAD2/3 and SARA thus interfering with the 


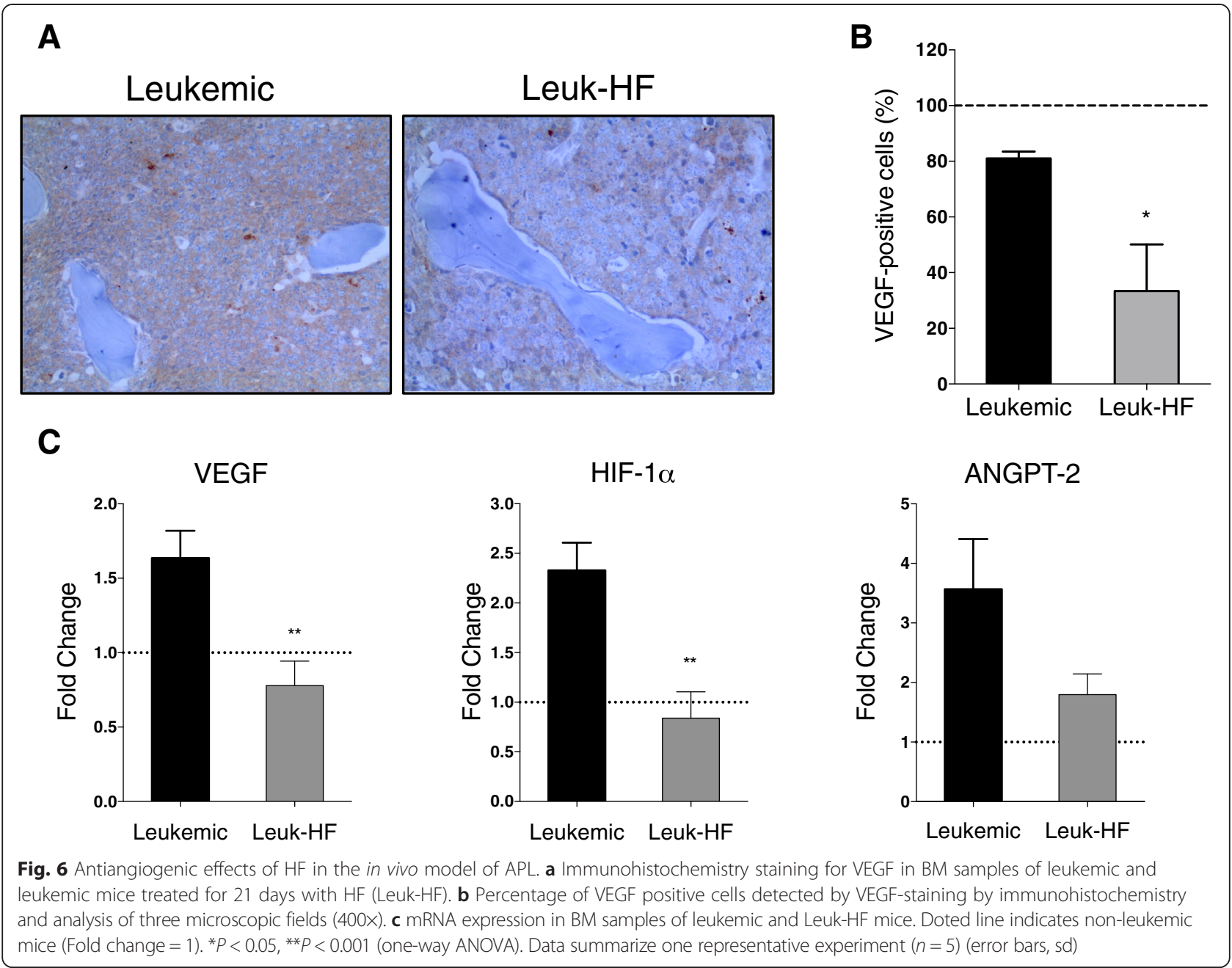

phosphorylation and nuclear translocation of this complex Lin et al. [26]. The authors hypothesized that PML/RAR $\alpha$ in the cytosol inhibits TGF- $\beta$-signaling by sequestering cPML away from the TF $\beta$ R1/SARA/SMAD2/3 complex thus preventing the trafficking to the early endosome. This inhibition could be further enhanced by interfering with nuclear isoform PML4, which has been demonstrated to transactivate TGF- $\beta$ target genes. Our results showed that NB4 cells responded to the addition of TGF- $\beta$ in culture medium with an increase of about 20-fold in SMAD2 phosphorylation. HF was capable of inhibiting TGF- $\beta$ induced SMAD2 phosphorylation. Taken together with our previous report that HF blocked NB4 proliferation and reduced the leukemia burden in vivo we postulated that despite the interference of PML/RAR $\alpha$ with TF $\beta R 1 /$ SARA/SMAD2/3 complex, the TGF- $\beta$ pathway remain active in APL and contributes for leukemia progression.

\section{Conclusion}

Here we showed HF can affect multiply mechanism and that $\mathrm{HF}$ treatment reduced proangiogenic factors expression and TGF- $\beta$-signaling in vitro, in addition to displaying antiangiogenic and antileukemic effects in an animal model of APL. Considering the importance of angiogenesis and deregulation of TGF- $\beta$-signaling in tumor progression, we propose $\mathrm{HF}$ as a potential new anti-cancer drug

\section{Additional files}

Additional file 1: Table S1. Vegf primers used for ChIP assay.
Additional file 2: Table S2. List of angiogenesis-related genes assessed
by PCR array.
Additional file 3: Figure S1. ChIP assay using antibodies to RNA
Polimerase II, Smad2/3, P-Smad2 and HIF-1a. NB4 cells were treated with
$200 \mathrm{ng} / \mathrm{mL}$ of HF for 6 hours, or treated with $200 \mathrm{ng} / \mathrm{mL}$ of HF for 6 hours
and stimulated with TGF- $\beta$ ( $1 \mathrm{ng} / \mathrm{mL}$ ) in the last hour, or only stimulated
with TGF- $\beta$. Graphics showing a PCR amplification of ChIP products for
(A) HIF-1a and (B) RNA Polimerase II antibodies using a series of primer
pairs covering the Vegf promoter. Data is represented as fold enrichment
to IgG control antibody.

Competing interests

The authors declare that they have no competing interests. 


\section{Authors' contributions}

5PAA and LLFP have equally contributed to the study. PAA, LLFP, NA and EMR: Conceived and designed the experiments; PAA, LLFP, ASGL, VL, LAC, CTP, ASGL and FPS: Performed the experiments; PAA, LLFP, VL, FPS and FC: Analyzed the data; RAP, FC, AN, RPF and EMR: Contributed reagents/ materials/analysis tools; PAA and EMR: Wrote the manuscript. All authors read and approved the final manuscript.

\section{Acknowledgements}

Halofuginone was obtained as a kind donation from Prof. Arnon Nagler Chaim Sheba Medical Center, Tel Hashomer, Israel. The transgenic hCG-PML-RARa mice were kindly provided by Prof. Pier Paolo Pandolfi (Beth Israel Deaconess Medical Center, Harvard Stem Cell Institute, Boston, MA USA). This work was supported by Fundação de Amparo à Pesquisa do Estado de São Paulo (FAPESP, grant No. 2013/08135-2). P.A.A. was an FAPESP fellowship recipient (Grant No. 08/52634-5).

\section{Author details}

${ }^{1}$ Hematology and Oncology Divisions of the Department of Internal Medicine, Medical School of Ribeirão Preto, University of São Paulo, Ribeirão Preto, SP 14049900, Brazil. ${ }^{2}$ Pathology Department, Medical School of Ribeirão Preto, University of São Paulo, Ribeirão Preto, SP 14049900, Brazil. ${ }^{3}$ Hematology Division and Cord Blood Bank, Chaim Sheba Medical Center, Tel Aviv University, Tel Hashomer 6997801, Israel.

Received: 19 September 2014 Accepted: 11 June 2015

Published online: 23 June 2015

\section{References}

1. De Figueiredo-Pontes $L L$, Assis PA, Santana-Lemos BA, Jacomo RH, Lima AS, Garcia $A B$, et al. Halofuginone has anti-proliferative effects in acute promyelocytic leukemia by modulating the transforming growth factor beta signaling pathway. PLoS One. 2011;6:e26713.

2. Chu TL, Guan Q, Nguan CY, Du C. Halofuginone suppresses T cell proliferation by blocking proline uptake and inducing cell apoptosis. Int Immunopharmacol. 2013;16:414-23.

3. Leiba M, Jakubikova J, Klippel S, Mitsiades CS, Hideshima T, Tai YT, et al. Halofuginone inhibits multiple myeloma growth in vitro and in vivo and enhances cytotoxicity of conventional and novel agents. Br J Haematol. 2012;157:718-31.

4. Abramovitch R, Dafni H, Neeman M, Nagler A, Pines M. Inhibition of neovascularization and tumor growth, and facilitation of wound repair, by halofuginone, an inhibitor of collagen type I synthesis. Neoplasia. 1999;1:321-9.

5. Elkin M, Miao HQ, Nagler A, Aingorn E, Reich R, Hemo I, et al. Halofuginone: a potent inhibitor of critical steps in angiogenesis progression. FASEB J. 2000;14:2477-85.

6. Abramovitch R, Itzik A, Harel H, Nagler A, Vlodavsky I, Siegal T. Halofuginone inhibits angiogenesis and growth in implanted metastatic rat brain tumor model-an MRI study. Neoplasia. 2004;6:480-9.

7. Folkman J. Tumor angiogenesis: therapeutic implications. N Engl J Med. 1971;285:1182-6

8. Jakovljevic G, Culic S, Stepan J, Bonevski A, Seiwerth S. Vascular endothelial growth factor in children with neuroblastoma: a retrospective analysis. J Exp Clin Cancer Res. 2009;28:143.

9. Ayala F, Dewar R, Kieran M, Kalluri R. Contribution of bone microenvironment to leukemogenesis and leukemia progression. Leukemia. 2009:23:2233-41.

10. Rajkumar SV, Witzig TE. A review of angiogenesis and antiangiogenic therapy with thalidomide in multiple myeloma. Cancer Treat Rev. 2000;26:351-62.

11. Jorgensen JM, Sorensen FB, Bendix K, Nielsen JL, Olsen ML, Funder AM, et al. Angiogenesis in non-Hodgkin's lymphoma: clinico-pathological correlations and prognostic significance in specific subtypes. Leuk Lymphoma. 2007:48:584-95.

12. Padro T, Ruiz S, Bieker R, Burger H, Steins M, Kienast J, et al. Increased angiogenesis in the bone marrow of patients with acute myeloid leukemia. Blood. 2000;95:2637-44.

13. Hatfield KJ, Olsnes AM, Gjertsen BT, Bruserud O. Antiangiogenic therapy in acute myelogenous leukemia: targeting of vascular endothelial growth factor and interleukin 8 as possible antileukemic strategies. Curr Cancer Drug Targets. 2005:5:229-48.

14. Aguayo A, Kantarjian HM, Estey EH, Giles FJ, Verstovsek S, Manshouri T, et al. Plasma vascular endothelial growth factor levels have prognostic significance in patients with acute myeloid leukemia but not in patients with myelodysplastic syndromes. Cancer. 2002;95:1923-30.

15. Kini AR, Peterson LA, Tallman MS, Lingen MW. Angiogenesis in acute promyelocytic leukemia: induction by vascular endothelial growth factor and inhibition by all-trans retinoic acid. Blood. 2001;97:3919-24.

16. Alimoghaddam K, Shariftabrizi A, Tavangar SM, Sanaat Z, Rostami S, Jahani $M$, et al. Anti-leukemic and anti-angiogenesis efficacy of arsenic trioxide in new cases of acute promyelocytic leukemia. Leuk Lymphoma. 2006;47:81-8.

17. Estey $\mathrm{E}$, Levine RL, Lowenberg B. Current challenges in clinical development of "targeted therapies": the case of acute myeloid leukemia. Blood. 2015;125:2461-6.

18. Estey EH, Giles FJ, Kantarjian H, O'Brien S, Cortes J, Freireich EJ, et al. Molecular remissions induced by liposomal-encapsulated all-trans retinoic acid in newly diagnosed acute promyelocytic leukemia. Blood. 1999:94:2230-5.

19. Lo-Coco F, Avvisati G, Vignetti M, Thiede C, Orlando SM, lacobelli S, et al. Retinoic acid and arsenic trioxide for acute promyelocytic leukemia. N Engl J Med. 2013;369:111-21.

20. Mathews V, Desire S, George B, Lakshmi KM, Rao JG, Viswabandya A, et al. Hepatotoxicity profile of single agent arsenic trioxide in the treatment of newly diagnosed acute promyelocytic leukemia, its impact on clinical outcome and the effect of genetic polymorphisms on the incidence of hepatotoxicity. Leukemia. 2006;20:881-3.

21. Ribeiro RC, Rego E. Management of APL in developing countries: epidemiology, challenges and opportunities for international collaboration. In: Hematology / the Education Program of the American Society of Hematology American Society of Hematology Education Program. 2006. p. 162-8.

22. Mathews V, George B, Chendamarai E, Lakshmi KM, Desire S, Balasubramanian $\mathrm{P}$, et al. Single-agent arsenic trioxide in the treatment of newly diagnosed acute promyelocytic leukemia: long-term follow-up data. J Clin Oncol. 2010;28:3866-71.

23. Tallman MS. Treatment of relapsed or refractory acute promyelocytic leukemia. Best Pract Res Clin Haematol. 2007;20:57-65.

24. Elkin M, Reich R, Nagler A, Aingorn E, Pines M, De-Groot N, et al. Inhibition of matrix metalloproteinase-2 expression and bladder carcinoma metastasis by halofuginone. Clin Cancer Res. 1999;5:1982-8.

25. Jordan MC, Zeplin PH. Local inhibition of angiogenesis by halofuginone coated silicone materials. J Mater Sci Mater Med. 2012;23:1203-10.

26. Lin HK, Bergmann S, Pandolfi PP. Cytoplasmic PML function in TGF-beta signalling. Nature. 2004;431:205-11.

27. Pepper MS. Transforming growth factor-beta: vasculogenesis, angiogenesis, and vessel wall integrity. Cytokine Growth Factor Rev. 1997;8:21-43.

28. Semenza GL. Expression of hypoxia-inducible factor 1: mechanisms and consequences. Biochem Pharmacol. 2000;59:47-53.

29. Xavier S, Piek E, Fujii M, Javelaud D, Mauviel A, Flanders KC, et al. Amelioration of radiation-induced fibrosis: inhibition of transforming growth factor-beta signaling by halofuginone. J Biol Chem. 2004;279:15167-76.

30. Sheffer $Y$, Leon O, Pinthus JH, Nagler A, Mor Y, Genin O, et al. Inhibition of fibroblast to myofibroblast transition by halofuginone contributes to the chemotherapy-mediated antitumoral effect. Mol Cancer Ther. 2007;6:570-7.

31. Taras D, Blanc JF, Rullier A, Dugot-Senant N, Laurendeau I, Bieche I, et al. Halofuginone suppresses the lung metastasis of chemically induced hepatocellular carcinoma in rats through MMP inhibition. Neoplasia. 2006:8:312-8.

32. Nagler A, Ohana M, Shibolet O, Shapira MY, Alper R, Vlodavsky l, et al. Suppression of hepatocellular carcinoma growth in mice by the alkaloid coccidiostat halofuginone. Eur J Cancer. 2004;40:1397-403.

33. He LZ, Tribioli C, Rivi R, Peruzzi D, Pelicci PG, Soares V, et al. Acute leukemia with promyelocytic features in PML/RARalpha transgenic mice. Proc Natl Acad Sci U S A. 1997:94:5302-7.

34. Lanotte $M$, Martin-Thouvenin V, Najman $S$, Balerini $P$, Valensi F, Berger R. NB4, a maturation inducible cell line with $t(15 ; 17)$ marker isolated from a human acute promyelocytic leukemia (M3). Blood. 1991;77:1080-6.

35. Wang $Y H$, Dong $Y Y$, Wang WM, Xie XY, Wang ZM, Chen RX, et al. Vascular endothelial cells facilitated HCC invasion and metastasis through the Akt 
and NF-kappaB pathways induced by paracrine cytokines. J Exp Clin Cancer Res. 2013;32:51.

36. Kunkel SL, Campbell Jr DA, Chensue SW, Higashi GI. Species-dependent regulation of monocyte/macrophage la antigen expression and antigen presentation by prostaglandin E. Cell Immunol. 1986;97:140-5.

37. Kogan SC, Ward JM, Anver MR, Berman JJ, Brayton C, Cardiff RD, et al. Bethesda proposals for classification of nonlymphoid hematopoietic neoplasms in mice. Blood. 2002;100:238-45.

38. Rego EM, Ruggero D, Tribioli C, Cattoretti G, Kogan S, Redner RL, et al. Leukemia with distinct phenotypes in transgenic mice expressing PML/RAR alpha, PLZF/RAR alpha or NPM/RAR alpha. Oncogene. 2006;25:1974-9.

39. Roberts AB. TGF-beta signaling from receptors to the nucleus. Microbes Infect. 1999;1:1265-73.

40. Santana BA, Pintao MC, Lima RS AE, Scheucher PS, Santos GA, Garcia AB, et al. Asynchronous expression of myeloid antigens in leukemic cells in a PML/RARalpha transgenic mouse model. Braz J Med Biol Res. 2006:39:615-20.

41. Dong $X$, Han ZC, Yang R. Angiogenesis and antiangiogenic therapy in hematologic malignancies. Crit Rev Oncol Hematol. 2007;62:105-18.

42. Elkin M, Ariel I, Miao HQ, Nagler A, Pines M, De-Groot N, et al. Inhibition of bladder carcinoma angiogenesis, stromal support, and tumor growth by halofuginone. Cancer Res. 1999;59:4111-8.

43. Ohayon O, Mawasi N, Pevzner A, Tryvitz A, Gildor T, Pines M, et al. Halofuginone upregulates the expression of heparanase in thioacetamide-induced liver fibrosis in rats. Lab Investig: J Tech Meth Pathol. 2008;88:627-33.

44. Bergers $G$, Benjamin LE. Tumorigenesis and the angiogenic switch. Nat Rev Cancer. 2003;3:401-10.

45. Schuch G, Machluf M, Bartsch Jr G, Nomi M, Richard H, Atala A, et al. In vivo administration of vascular endothelial growth factor (VEGF) and its antagonist, soluble neuropilin-1, predicts a role of VEGF in the progression of acute myeloid leukemia in vivo. Blood. 2002;100:4622-8.

46. Oka Y, Tashiro H, Shirasaki R, Sugao T, Nishi R, Akiyama N, et al. Vascular endothelial growth factor acted as autocrine growth factor in an acute promyelocytic leukemia case. Leuk Lymphoma. 2010;51:717-9.

47. Ossenkoppele GJ, Stussi G, Maertens J, Van Montfort K, Biemond BJ, Breems $D$, et al. Addition of bevacizumab to chemotherapy in acute myeloid leukemia at older age: a randomized phase 2 trial of the Dutch-Belgian Cooperative Trial Group for Hemato-Oncology (HOVON) and the Swiss Group for Clinical Cancer Research (SAKK). Blood. 2012;120:4706-11.

48. You WK, McDonald DM. The hepatocyte growth factor/c-Met signaling pathway as a therapeutic target to inhibit angiogenesis. BMB Rep. 2008; $41: 833-9$

49. Du R, Lu KV, Petritsch C, Liu P, Ganss R, Passegue E, et al. HIF1alpha induces the recruitment of bone marrow-derived vascular modulatory cells to regulate tumor angiogenesis and invasion. Cancer Cell. 2008;13:206-20.

50. Chen P, Yang LL, Yang HS, Wang YS, Li G, Wu Y, et al. Synergistic antitumor effect of CXCL10 with hyperthermia. J Cancer Res Clin Oncol. 2008;134:679-87.

51. Scrideli CA, Cortez MA, Yunes JA, Queiroz RG, Valera ET, Da Mata JF, et al. mRNA expression of matrix metalloproteinases (MMPs) 2 and 9 and tissue inhibitor of matrix metalloproteinases (TIMPs) 1 and 2 in childhood acute lymphoblastic leukemia: potential role of TIMP1 as an adverse prognostic factor. Leuk Res. 2010;34:32-7.

52. Gavish Z, Pinthus JH, Barak V, Ramon J, Nagler A, Eshhar Z, et al. Growth inhibition of prostate cancer xenografts by halofuginone. Prostate. 2002;51:73-83.

53. Grudzien MM, Low PS, Manning PC, Arredondo M, Belton Jr RJ, Nowak RA. The antifibrotic drug halofuginone inhibits proliferation and collagen production by human leiomyoma and myometrial smooth muscle cells. Fertil Steril. 2010;93:1290-8

54. McGaha TL, Phelps RG, Spiera H, Bona C. Halofuginone, an inhibitor of type-I collagen synthesis and skin sclerosis, blocks transforming-growthfactor-beta-mediated Smad3 activation in fibroblasts. J Invest Dermatol. 2002;118:461-70

55. Roffe S, Hagai Y, Pines M, Halevy O. Halofuginone inhibits Smad3 phosphorylation via the PI3K/Akt and MAPK/ERK pathways in muscle cells: effect on myotube fusion. Exp Cell Res. 2010:316:1061-9.

56. Juarez P, Mohammad KS, Yin JJ, Fournier PG, McKenna RC, Davis HW, et al. Halofuginone inhibits the establishment and progression of melanoma bone metastases. Cancer Res. 2012;72:6247-56.
57. Kobayashi T, Liu X, Wen FQ, Fang Q, Abe S, Wang XQ, et al. Smad3 mediates TGF-beta1 induction of VEGF production in lung fibroblasts. Biochem Biophys Res Commun. 2005;327:393-8.

58. Jeon SH, Chae BC, Kim HA, Seo GY, Seo DW, Chun GT, et al. Mechanisms underlying TGF-beta1-induced expression of VEGF and Flk-1 in mouse macrophages and their implications for angiogenesis. J Leukoc Biol. 2007:81:557-66.

59. Clifford RL, Deacon K, Knox AJ. Novel regulation of vascular endothelia growth factor-A (VEGF-A) by transforming growth factor (beta)1: requirement for Smads, (beta)-CATENIN, AND GSK3(beta). J Biol Chem. 2008;283:35337-53.

60. Pepper MS, Vassalli JD, Orci L, Montesano R. Biphasic effect of transforming growth factor-beta 1 on in vitro angiogenesis. Exp Cell Res. 1993;204:356-63.

\section{Submit your next manuscript to BioMed Central and take full advantage of:}

- Convenient online submission

- Thorough peer review

- No space constraints or color figure charges

- Immediate publication on acceptance

- Inclusion in PubMed, CAS, Scopus and Google Scholar

- Research which is freely available for redistribution 